\title{
Nogo-A-targeting antibody promotes visual recovery and inhibits neuroinflammation after retinal injury
}

\author{
Julius Baya Mdzomba', Sandrine Joly', Léa Rodriguez ${ }^{1}$, Ali Dirani ${ }^{1}$ Patricia Lassiaz², Francine Behar-Cohen ${ }^{2}$ and \\ Vincent Pernet $\mathbb{B D}^{1}$
}

\begin{abstract}
N-Methyl-D-aspartate (NMDA)-induced neuronal cell death is involved in a large spectrum of diseases affecting the brain and the retina such as Alzheimer's disease and diabetic retinopathy. Associated neurological impairments may result from the inhibition of neuronal plasticity by Nogo-A. The objective of the current study was to determine the contribution of Nogo-A to NMDA excitotoxicity in the mouse retina. We observed that Nogo-A is upregulated in the mouse vitreous during NMDA-induced inflammation. Intraocular injection of a function-blocking antibody specific to Nogo-A (11C7) was carried out 2 days after NMDA-induced injury. This treatment significantly enhanced visual function recovery in injured animals. Strikingly, the expression of potent pro-inflammatory molecules was downregulated by 11C7, among which TNFa was the most durably decreased cytokine in microglia/macrophages. Additional analyses suggest that TNFa downregulation may stem from cofilin inactivation in microglia/macrophages. $11 \mathrm{C7}$ also limited gliosis presumably via P.Stat3 downregulation. Diabetic retinopathy was associated with increased levels of Nogo-A in the eyes of donors. In summary, our results reveal that Nogo-A-targeting antibody can stimulate visual recovery after retinal injury and that Nogo-A is a potent modulator of excitotoxicity-induced neuroinflammation. These data may be used to design treatments against inflammatory eye diseases.
\end{abstract}

\section{Introduction}

Excitotoxic cell death mediated by N-methyl-Daspartate (NMDA) receptor activation plays a central role in the neurodegenerative diseases affecting the CNS, including the retina ${ }^{1-4}$. In retinal diseases such as diabetic retinopathy, irreversible visual deficits have been linked to NMDA receptor overactivation ${ }^{5-7}$ that results in the death of retinal ganglion cells (RGCs), the output neurons of the retina that normally ensure the transfer of visual

\footnotetext{
Correspondence: Vincent Pernet (vincent.pernet@yahoo.ca)

${ }^{1}$ CUO-Recherche, Centre de recherche du CHU de Québec-Université Laval and Département d'ophtalmologie, Faculté de médecine, Université Laval, Québec, Québec, Canada

Inserm UMR_S 1138, Team 17, Centre de Recherche des Cordeliers, Paris Descartes University, Sorbonne University, and University of Pierre et Marie Curie, Paris, France

These authors contributed equally: Julius Baya Mdzomba, Sandrine Joly Edited by A Verkhratsky
}

information from the eye to the brain ${ }^{8,9}$. The toxic levels of glutamate in diabetic retinal ${ }^{7}$ and vitreous ${ }^{5}$ samples are due to the defects in glutamate detoxification ${ }^{7}$ and reuptake ${ }^{10}$ by glial cells. Consistently, intravitreal injections of NMDA in rodents is a classical model to study the mechanisms of excitotoxity in the retina ${ }^{8,11-13}$.

In the present study, we wondered if Nogo-A influenced the development of excitotoxic damage in the retina. Nogo-A is a potent myelin-associated inhibitor for neuronal plasticity and axonal regeneration in the injured $\mathrm{CNS}^{14,15}$. At the molecular level, three distinct inhibitory domains of Nogo-A have been identified ${ }^{16}$. In its N-term part, Nogo-A contains an amino acid sequence inhibiting fibroblast cell spreading. A specific central region of the protein called Nogo-A-Delta 20 restricts cell spreading and neurite outgrowth and a C-term domain called Nogo66 promotes growth cone collapse. The cell transduction 
mechanisms of Nogo-A depend on the interaction between its three domains and different receptor partners. Nogo-66 binds and activates a receptor complex composed of Nogo-66 receptor $1(\mathrm{NgR} 1)^{17}$, Lingo- $1^{18}$ and p75/Troy ${ }^{19,20}$ leading to actin cytoskeleton disassembly via the small GTPase RhoA ${ }^{21}$. On the other hand, NogoA-Delta 20 can be a ligand for sphingosine 1-phosphate receptors $(\mathrm{S} 1 \mathrm{PR})^{22}$. Its binding to S1PR2 intracellularly activates the RhoA-ROCK pathway in fibroblasts and neuronal cells. Targeting Nogo-A-Delta 20 with neutralizing antibodies such as $11 \mathrm{C} 7$ was shown to promote neurological recovery in experimental models of stroke $\mathrm{e}^{23-25}$ and spinal cord injury ${ }^{26,27}$.

The involvement of Nogo-A in pathological mechanisms affecting the retina suggests that Nogo-A-targeting antibodies may also improve vision in ocular diseases. Our recent results revealed that blocking Nogo-A-Delta 20 with intravitreal injection of $11 \mathrm{C} 7$ antibody dramatically increased vascular repair and neuronal function in the retina of mice subjected to ischemic retinopathy ${ }^{28}$. In adult mice, we also reported that Nogo-A KO mice had better visual recovery after retinal injury than WT ani$\mathrm{mals}^{29}$. Here, we hypothesized that retinal Nogo-A may inhibit injured neuron repair ${ }^{28,30-33}$. Indeed, immunofluorescent observations revealed high levels of Nogo-A in radial Müller glia, a specialized retinal glia, and to a lower extent in RGCs.

In this study, retinal injury caused the simultaneous release of Nogo-A and TNF $\alpha$ in the mouse vitreous. Neutralizing Nogo-A-Delta 20 with intravitreal injection of 11C7 improved visual function recovery and strongly reduced inflammation at the same time. Importantly, Nogo-A was dramatically increased in the retina and in the vitreous humor of donors suffering from diabetic retinopathy. Taken together, these results unveil a new function of Nogo-A in retinal inflammation.

\section{Materials and methods \\ Animals}

In this study, adult male C57BL/6J mice were purchased from the Jackson Laboratory and were used at 2-4 months of age. All animal experiments were carried out in accordance with the guidelines of the Canadian Council on Animal Care and of the Animal Welfare Committee of the Université Laval.

\section{Intraocular injections}

To induce retinal injury, $2 \mu \mathrm{l}$ of NMDA $(0.5-40 \mathrm{nmol})$ were injected in the left eye using a 10- $\mu$ l Hamilton syringe, under general anesthesia with isoflurane, as previously described ${ }^{29,32-35}$. In brief, the glass tipped needle was delicately inserted through the sclera of the eyeball by taking care not to injure the lens. To allow NMDA diffusion in the vitreous and limit its backflow, the needle was held in place for $3 \mathrm{~min}$ and then slowly withdrawn. A drop of surgical glue (Histoacry ${ }^{\circledR}$, Braun) was applied to seal the injection site. The same procedure was used for the injection of the function-blocking antibody 11C7 (IgG1 serotype, $2 \mu \mathrm{g} /$ eye, a gift from Prof Martin Schwab, Univ Zurich,), raised against Nogo-A-Delta $20^{16}$, or control IgG (IgG1 serotype, clone FG12/B5, $2 \mu \mathrm{g} /$ eye, Antibody Production Service Ltd ${ }^{29}, 2$ days after NMDA injection.

\section{Optokinetic reflex test}

To evaluate the visual acuity of freely moving mice, the optokinetic reflex was tested using OptoDrum system (Striatech GmbH Vor dem Kreuzberg, Tübingen, Germany). In brief, mice (6-9/group) were placed on a platform in the middle of an arena surrounded by four computer screens while moving gratings of different spatial frequencies were passed on the monitors ${ }^{36,37}$. The reflexive tracking movement of the mouse neck in the temporal-to-nasal direction allowed to evaluate the visual response of the two eyes separately by changing the direction of the visual stimulus. For statistical analysis, a two-way ANOVA was applied (GraphPad Prism, GraphPad Software, La Jolla, CA, USA).

\section{Electroretinogram (ERG) recording}

A Ganzfeld system (Phoenix Research Labs, Pleasanton, CA, USA) was used to record photopic ERGs in mice (5-9/group) anesthetized with a ketamine/xylazine mixture, as described before ${ }^{28,38}$. Prior to recording, a drop of $1 \%$ Mydriacyl Tropicamide was applied on the cornea for pupil dilation. A sterile ophthalmic gel (Tear-Gel, Baush \& Lomb) was used to prevent corneal desiccation and to allow the contact between the cornea and the electrode (gold-plate objective lens). ERGs were generated in response to flash stimulations of increasing intensities, ranging from $1.0 \log$ cd.s. $\mathrm{m}^{2}$ to $2.8 \log$ cd.s.m ${ }^{2}$ (inter-stimulus interval, $20 \mathrm{~ms}$; flash duration, $1 \mathrm{~ms}$; average of 20 flashes, 0.6 log-unit increment). The use of green $(504 \mathrm{~nm})$ and UV $(365 \mathrm{~nm})$ lights allowed to record Mcone and the S-cone-dependent ERG waveforms respectively. The amplitude of the b-wave was measured from the a-wave trough to the highest peak. Statistical analysis was performed using a two-way ANOVA followed by Tukey post hoc test (GraphPad Prism).

\section{Tissue preparation for histological analysis}

Mice were euthanized using a lethal dose of ketamine/ xylazine mixture $(90-10 \mathrm{mg} / \mathrm{kg}$ ). Tissues were fixed by intracardial perfusion of phosphate-buffered saline (PBS) and 4-\% paraformaldehyde (PFA) solutions. Eyes and optic nerves were dissected for retinal and optic nerve sections (14- $\mu \mathrm{m}$ thick), or retinal flat-mount preparation. 


\section{Retinal ganglion cell (RGC) and amacrine cell survival}

The survival of RGCs and amacrine cells was evaluated 43 days after NMDA injection on retinal flat-mounts of 6-9 mice for each experimental group. Retinal flatmounts were post-fixed overnight in 4\% PFA, rinsed with PBS three times, incubated for $1 \mathrm{~h}$ in a blocking solution (PBS containing $5 \%$ bovine serum albumin (BSA), 0.3\% Triton X-100, and $0.01 \%$ sodium azide) and incubated for 5 days at room temperature with the following primary antibodies: rabbit anti-RNA binding protein with multiple splicing (RBPMS) (1:200, PhosphoSolutions, Aurora, CO, USA, \#1830-RBPMS) or goat anti-choline acetyltransferase (ChAT) (1:100, Millipore, \#AB144P). After intensive washing, retinal flat-mounts were incubated for 2 days at room temperature with appropriate secondary antibodies diluted in the blocking solution. Vectashield solution (BioLynx, Brockville, ON, Canada) was used as a mounting medium. Cells were counted in regions of $62,500 \mu \mathrm{m}^{2}$ at $0.5,1,1.5$, and $2 \mathrm{~mm}$ from the optic disk in the four retinal quadrants. Statistical differences were evaluated using an unpaired $t$-test (GraphPad Prism).

\section{Immunofluorescence on retinal and optic nerve cryosections}

Retinal eye cups and optic nerves were post-fixed overnight in $4 \%$ PFA and immersed in a solution of $30 \%$ of sucrose for cryo-protection before tissue embedding in optimal cutting temperature (Cedarlane, Burlington, ON, Canada) medium. 14- $\mu \mathrm{m}$ thick cryosections were collected on Superfrost microscope glass slides. For immunostaining, tissue slices were incubated for $1 \mathrm{~h}$ in a blocking solution and then overnight with primary antibodies at $4{ }^{\circ} \mathrm{C}$ (see Table 1 ). After three washes with PBS sections were incubated at room temperature with the appropriate secondary antibodies. Slides were mounted with the Vectashield mounting medium. For microscopy and image acquisition, mosaic pictures were taken with a Zeiss AxioImager M2 microscope equipped with a motorized platform and the ZEN software and a LSM 700 scanning confocal microscope (Zeiss). All quantifications were performed using 5-6 central retinal or optic nerve cuts/mouse. At least 3 mice were used per experimental condition. In quantitative analyses, statistical significance was evaluated using a one-way ANOVA followed by Dunnett's post hoc test.

\section{Western blot analysis}

Retinae were quickly isolated from the eyes, snap frozen in liquid nitrogen and stored at $-80^{\circ} \mathrm{C}$ until protein lysate preparation. Retinae were homogenized for $60 \mathrm{~min}$ on ice in Eppendorf tubes containing lysis buffer $(20 \mathrm{mM}$ Tris$\mathrm{HCl}, 0.5 \%$ CHAPS, $\mathrm{pH}$ 8.0) and protease/phosphatase inhibitor (Roche Diagnostics, Laval, QC, Canada) and centrifuged for $15 \mathrm{~min}$ at $15,000 \times g$ at $4{ }^{\circ} \mathrm{C}$. Supernatants were then retrieved and used for protein assay (BioRad, Mississauga, ON, Canada). Retinal proteins $(20 \mu \mathrm{g} /$ well $)$ were resolved by electrophoresis on $4-12 \%$ gradient polyacrylamide gels and transferred to nitrocellulose membranes. Nitrocellulose membranes were preincubated in a blocking solution of 5\% BSA dissolved in TBST (Tris-base $0.1 \mathrm{M}, 0.2 \%$ Tween 20, $\mathrm{pH} \mathrm{7.4)} \mathrm{for} 1 \mathrm{~h}$ at room temperature, incubated with primary antibodies overnight at $4{ }^{\circ} \mathrm{C}$ (see Table 1). After washes, membranes were incubated with a horseradish peroxidase-conjugated anti-mouse or anti-rabbit antibody (1:10 000; Pierce Biotechnology, Burlington, ON, Canada). Chemiluminescent bands were detected with LiCor Western Sure Premium Chemiluminescent Substrate (Mandel, Guelph, ON, Canada) in a LiCor C-Digit blot scanner (Mandel). Band signals were quantified with the ImageJ software and analyzed with the GraphPad Prism software. To study the dose-dependent effects of NMDA on retinal protein expression changes, 3 mice were used for each experimental condition. In this case, statistics were done using a one-way ANOVA followed by Dunnett's post hoc test (GraphPad Prism). The effects of $11 \mathrm{C} 7$ and control IgG were analyzed in retinal and vitreous lysates using 3-5 mice per group, as indicated in the figure legends. Statistical analysis was performed using an unpaired $t$-test (GraphPad Prism).

\section{Semi-qRT-PCR}

Animals were sacrificed by cervical dislocation and tissue rapidly obtained before being flash-frozen in liquid nitrogen. Eppendorf tubes of the tissue collected were stored at $-80^{\circ} \mathrm{C}$ until RNA could be extracted. To prepare total retinal RNA, an RNeasy isolation kit (Qiagen, Toronto, ON, Canada) was used. Residual genomic DNA was eliminated by use of a DNase treatment. Oligo (dt) and M-MLV reverse transcriptase (Fisher Scientific) was used to transform equal amounts of RNA for reverse transcription. Amplification of ten nanograms of cDNA with the SYBR Green I Master polymerase ready mix (Roche Diagnostics Canada) was done using the Light Cycler 480 thermocycler (Roche Diagnostics Canada). Primer pairs were made to span the intronic sequences or to cover exon-intron boundaries (see Table 2 for sequences). The comparative threshold cycle $(\Delta \Delta \mathrm{CT})$ method was used to calculate the relative quantification. As a reference gene and control sample, Gapdh was used to normalize cDNA levels. Each reaction was done in triplicate for 4-6 mice per condition. Statistical analysis was performed by applying an unpaired $t$-test (GraphPad Prism).

\section{Human retina histology and vitreous analyses}

All patients involved in the study signed an informed consent prior to vitreous or retinal use. Experiments 
Table 1 Antibodies used for immunofluorescence (IF) and western blotting (WB).

\begin{tabular}{|c|c|c|c|c|c|}
\hline Name & Species & Dilution IF & Dilution WB & Source & Catalog \# \\
\hline RBPMS & Guinea pig & $1: 200$ & & PhosphoSolutions (Aurora, CO) & 1832-RBPMS \\
\hline RBPMS & Rabbit & $1: 200$ & & PhosphoSolutions (Aurora, CO) & 1830-RBPMS \\
\hline P.Stat3 & Rabbit & $1: 100$ & $1: 500$ & Cell Signaling & 9131 \\
\hline Stat3 & Rabbit & & 1:1 000 & Cell Signaling & $\mathrm{D} 3 \mathrm{Z} 2 \mathrm{G}$ \\
\hline P.cofilin & Rabbit & $1: 200$ & 1:1 000 & Cell Signaling & 3313 \\
\hline Cofilin & Rabbit & & 1:1 000 & Cell Signaling & 5175 \\
\hline |ba-1 & Rabbit & $1: 200$ & & Wako & 019-19741 \\
\hline |ba-1 & Goat & 1:1 000 & & Novus Biologicals & NB100-1028 \\
\hline Isolectin b4 & & $1: 100$ & & Life Technologies & 121413 \\
\hline GFAP & Rabbit & $1: 500$ & & Dako & Z-0334 \\
\hline Glutamine synthetase & mouse & 1: 500 & & Millipore & MAB302 \\
\hline P.Erk & Rabbit & $1: 100$ & 1:1 000 & Cell Signaling & 4370 \\
\hline Erk & Rabbit & & 1:1 000 & Cell Signaling & 4595 \\
\hline TNFa & Mouse & $1: 200$ & & Abcam & ab1793 \\
\hline TNFa & Rabbit & & $1: 1000$ & Abcam & ab2148P \\
\hline CD68 & Rat & 1:1 000 & & Abcam & ab53444 \\
\hline Nogo-A & Rabbit & & 1:1 000 & Abcam & Ab47085 \\
\hline Nogo-A (Rtn4) & Rabbit & $1: 200$ & 1:2 000 & Dr. M. Schwab & Rb173A (Laura) \\
\hline Nogo-A & Rabbit & & $1: 20000$ & Dr. M. Schwab & Rb1 (Bianca) \\
\hline Nogo-A & Sheep & & 1:5000 & Dr. M. Schwab & S544 \\
\hline Nogo-A & Mouse & $1: 200$ & $1: 2000$ & Dr. M. Schwab & $11 C 7$ \\
\hline Olig2 & Rabbit & $1: 500$ & & Millipore & AB9610 \\
\hline Smi-32 & Mouse & $1: 500$ & & Millipore & NE1023 \\
\hline GAPDH & Mouse & & $1: 20000$ & Abcam & ab8245 \\
\hline
\end{tabular}

with human samples have been approved by the Comité d'éthique de la recherche du CHU de Québec-Université Laval. For immunofluorescence observations, human retinal sections were obtained from a french eye bank association (Banque française des yeux, Paris, France). Paraffin sections were cut from the eye of a non-diabetic, 71-year-old male donor. The cause of the death was renal insufficiency. Diabetic retinal sections came from a 85-year old male donor suffering from type 2 diabetes, treated with insulin and presenting nonproliferative diabetic retinopathy with macular edema. The origin of the death was lung carcinoma. For the two donors, retinae where collected up to $20 \mathrm{~h}$ post-mortem. Retinal cross sections were stained for glutamine synthetase (GS antibody, 1:300, MAB 302, Chemicon Technology, Merck Millipore, Billerica, Massachusetts, USA), for glial fibrillary acidic protein (GFAP antibody,
1:300, Abcam, ab49874, Cambridge, UK) and Nogo-A (11C7 antibody, 1:200). For the detection of Nogo-A in the human vitreous, vitreous samples were collected by an experienced ophthalmologist of the Hôpital du SaintSacrement of the Centre Universitaire d'ophtalmologie in Quebec City, Canada. Analyzed samples were obtained from two non-diabetic male patients of 73 and 75 years of age treated for retinal detachment and epiretinal membrane, respectively. Vitreous of diabetic patients were obtained from a 77-year-old man, without diabetic retinopathy, and from a 68-year-old woman with proliferative diabetic retinopathy. To monitor the protein level of Nogo-A, fifteen microliters of vitreous was analyzed by western blot using $11 \mathrm{C} 7$ antibody (1:2000). The ability of $11 \mathrm{C} 7$ to detect human Nogo-A was validated using recombinant Nogo-A protein (Abcam, ab163499). 
Table 2 Primer sequences used for qRT-PCR measurements.

\begin{tabular}{|c|c|c|c|}
\hline Gene Names & Sequence forward $\left(5^{\prime}-3^{\prime}\right)$ & Sequence reverse $\left(5^{\prime}-3^{\prime}\right)$ & Product (bp) \\
\hline Aif1 & GGAGACGTTCAGCTACTCTGAC & GCCCTGATTGGAGGTGGATG & 163 \\
\hline Atf3 & ACCTCCTGGGTCACTGGTATTTG & TTCTTTCTCGCCGCCTCCTTTTCC & 215 \\
\hline Bdnf & CAAAGCCACAATGTTCCACCAG & GATGTCGTCGTCAGACCTCTCG & 213 \\
\hline $\mathrm{CCl} 2$ & GGCTCAGCCAGATGCAGTTA & CTGCTGCTGGTGATCCTCTT & 108 \\
\hline CD68 & ACCTACATCAGAGCCCGAGTACAG & TTCTGCGCCATGAATGTCCACTG & 100 \\
\hline Cntf & CTCTGTAGCCGCTCTATCTG & GGTACACCATCCACTGAGTC & 125 \\
\hline $\operatorname{cox} 2$ & GACAGATCATAAGCGAGGAC & TACACCTCTCCACCAATGAC & 153 \\
\hline Csf1 & GCTCCAGGAACTCTCCAATA & TCTTGATCTTCTCCAGCAGC & 119 \\
\hline $\mathrm{C} \times 3 \mathrm{cl} 1$ & CCGCGTTCTTCCATTTGT & CTGTGCTGTGTCGTCTCCA & 175 \\
\hline$F 4 / 80$ & TGGGACAAACACTTGGTGGTGTG & GTGTCAGTGCAGGTGGCATAAG & 76 \\
\hline Gapdh & CAGCAATGCATCCTGCACC & TGGACTGTGGTCATGAGCCC & 96 \\
\hline Gap43 & TGCTGTCACTGATGCTGCT & GGCTTCGTCTACAGCGTCTT & 127 \\
\hline Gfap & CCACCAAACTGGCTGATGTCTAC & TTCTCTCCAAATCCACACGAGC & 240 \\
\hline $11-16$ & GCTATGGCAACTGTTCCTGA & GATGTGCTGCTGCGAGATT & 171 \\
\hline Lif & AATGCCACCTGTGCCATACG & CAACTTGGTCTTCTCTGTCCCG & 216 \\
\hline Rtn4 & CAGTGGATGAGACCCTITTG & GCTGCTCCTTCAAATCCATAA & 90 \\
\hline Rtn $4 r$ & CTCGACCCCGAAGATGAAG & TGTAGCACACACAAGCACCAG & 116 \\
\hline Sipr1 & TCAGGGAACTITGCGAGTGA & AACAGCAGCCTCGCTCAAG & 123 \\
\hline Sipr2 & CATCGCCATCGAGAGACAAG & TCAGACAATTCCAGCCCAGG & 146 \\
\hline Sprria & GAACCTGCTCTTCTCTGAGT & AGCTGAGGAGGTACAGTG & 91 \\
\hline Sphk1 & ATACTCACCGAACGGAAGAAC & ATTAGCCCATTCACCACCTC & 122 \\
\hline Sphk2 & GCTTTACGAGGTGCTGAATG & AGAAGCGAGCAGTTGAG & 174 \\
\hline Stat3 & CAAAACCCTCAAGAGCCAAGG & TCACTCACAATGCTTCTCCGC & 139 \\
\hline Tnf & CCACGCTCTTCTGTCTACTGA & GGCCATAGAACTGATGAGAGG & 92 \\
\hline Tubb3 & GGCCTCCTCTCACAAGTATG & TTGCCAGCACCACTCTGAC & 138 \\
\hline Vim & TACAGGAAGCTGCTGGAAGG & TGGGTGTCAACCAGAGGAA & 113 \\
\hline
\end{tabular}

\section{Results}

Retinal excitotoxicity increases the level of Nogo-A

\section{proteins in the vitreous of mice}

Nogo-A is endogenously expressed in Müller glia and ganglion cell (RGC) bodies ${ }^{30,32,33}$. By immunofluorescence and western blotting (Fig. 1), we set out to determine if NMDA-induced neuronal cell death was associated with changes in Nogo-A localization and expression. Three hours after NMDA intravitreal injection ( $2 \mathrm{nmol} / \mathrm{eye}), \mathrm{RGC}$ lysis was established by the observation of fragments labeled with RNA-binding protein with multiple splicing (RBPMS), a protein selectively localized in the soma of $\mathrm{RGCs}^{39}$, suggesting quick extracellular spill of RGC cytoplasm after excitotoxicity induction (Fig. 1a). On retinal cross sections, $24 \mathrm{~h}$ after NMDA-induced injury, many large soma-sized RGCs expressing RBPMS and Nogo-A were lost (Fig. 1b, c). In NMDA-treated animals, remaining RGCs displayed a weak signal for Nogo-A (Fig. 1b, c, arrow). However, Nogo-A fluorescent signal was not much different in Müller cell processes labeled with glutamine synthetase (GS), compared with that observed in intact or PBSinjected retinae. To further investigate the possible release of Nogo-A following NMDA-induced RGC lysis, a Western blot analysis of retinal and vitreal lysates was undertaken (Fig. 1d-g). The level of Nogo-A protein did not significantly change after the injection of increasing doses of NMDA in the vitreous humor (Fig. 1d). The phosphorylation of Stat3 and Erk1/2 has been shown to participate in the neuronal and glial response to retinal injury $^{12,40-42}$ and was thus used to monitor the reaction of retinal cells to NMDA injury. We observed that P.Stat3 

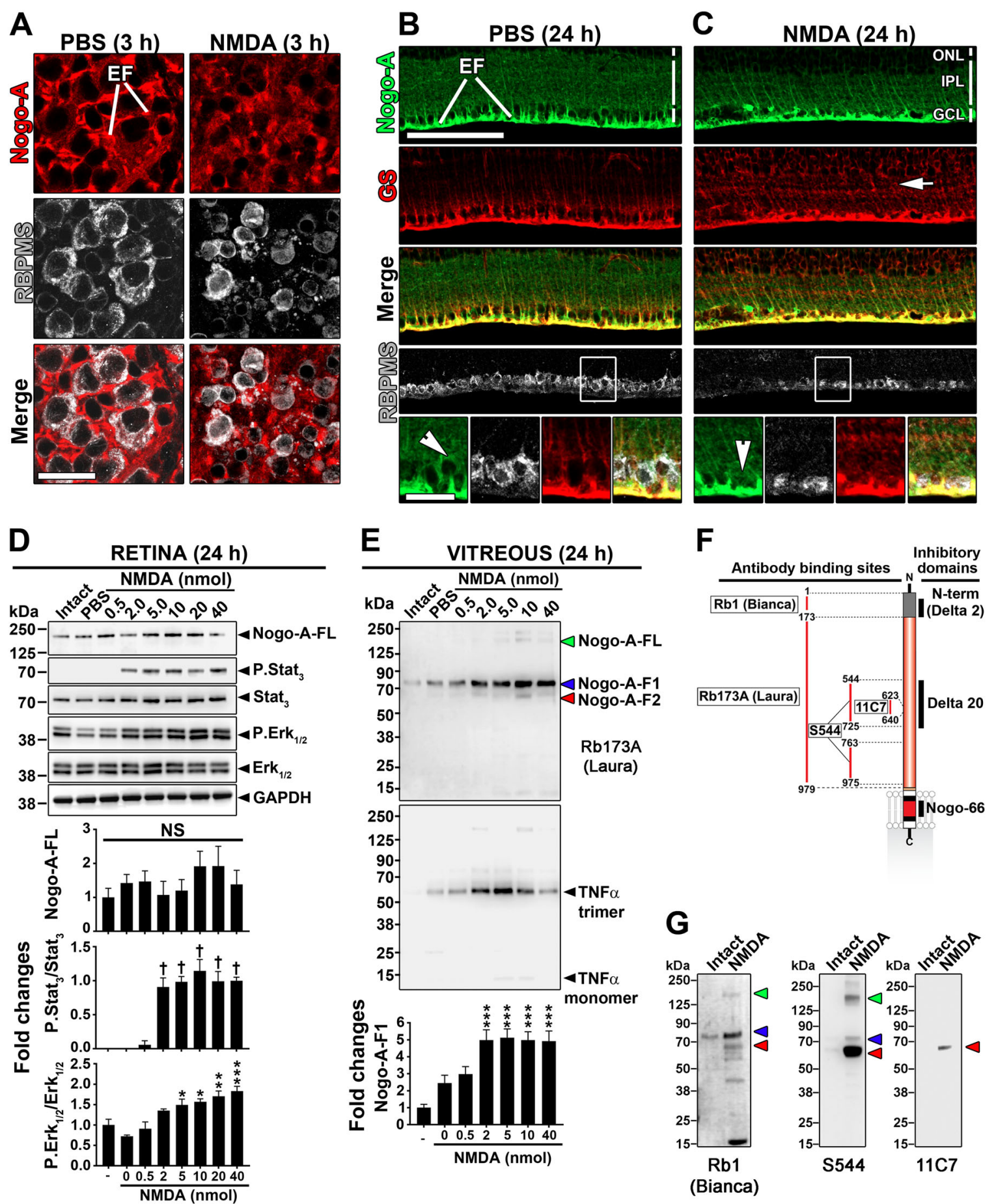

Fig. 1 (See legend on next page.)

and P.Erk1/2 were upregulated by NMDA in a dosedependent manner (Fig. 1d). In contrast, the lack of change for Nogo-A (Fig. 1d) is attributable to stable expression in Müller glia, i.e. the cells constituting the main source of this protein in the whole retina ${ }^{30-33}$. Strikingly, however, Nogo-A proteins dose-dependently increased in the vitreous of eyes treated with NMDA (Fig. 1e). The Nogo-A proteins observed in the vitreous 
(see figure on previous page)

Fig. 1 Retinal injury induces Nogo-A protein release in the mouse vitreous. a-c Compared with intact condition (no treatment) and PBS treatment, intravitreal injection of NMDA induced the loss of retinal ganglion cells expressing Nogo-A and the specific cell marker RBPMS. In contrast, glial expression of Nogo-A did not change in glutamine synthetase (GS)-expressing Müller cells after NMDA-induced injury. Three mice per condition were examined. $\mathbf{d}$ By Western Blotting, the level of Nogo-A protein did not significantly change in retinal lysates treated with increasing doses of NMDA (0-40 nmoles) although P.Stat ${ }_{3}$ and P.Erk $1 / 2$ were upregulated in a dose-dependent manner in response to retinal damage. e Western Blot analysis of mouse vitreous ( $4 \mathrm{\mu L} /$ well) revealed that NMDA induced the increase of Nogo-A and TNFa proteins in a dose-dependent manner. For quantitative analysis, 3 mice were used per condition. With Rb173A antibody which recognizes the Nogo-A specific domain encoded by exon 3, 4 proteins were observed at $\sim 80 \mathrm{kDa}$ (Nogo-A-F1), $\sim 68 \mathrm{kDa}$ (Nogo-A-F2), and at $\sim 200-250 \mathrm{kDa}$ (Full-length Nogo-A, Nogo-A-FL). Strikingly, TNFa appeared predominantly in trimers, i.e. under its most inflammatory form. $\mathbf{f}, \mathbf{g}$ Additional antibodies directed against different parts of Nogo-A, named Rb1, S544, and 11C7, were used to determine the presence of Nogo-A proteins in the vitreous of NMDA-treated eyes. Increased levels of Nogo-A proteins were thus confirmed. Interestingly, proteins of similar molecular weight were found and may correspond to Nogo-A-F1, Nogo-A-F2, and Nogo-A-FL. Statistics: One-way ANOVA, Dunnett's post hoc test, ${ }^{*} P<0.05 ;{ }^{*} P<0.01 ;{ }^{* *} P<0.001 ;{ }^{\dagger} P<0.0001$. Scale bars: a, b close-up (bottom left) $=25 \mu \mathrm{m} ; \mathbf{b}$ (top left) $=100 \mu \mathrm{m}$.

were full-length Nogo-A and protein fragments that were named Nogo-A-F1 and Nogo-A-F2. Similar Nogo-A proteins could be detected in the vitreous of NMDAinjected eyes using antibodies recognizing its three inhibitory domains (Fig. 1f, g). Coincidental increase of the TNF $\alpha$ cytokine level suggests a link between retinal inflammation and Nogo-A elevation in the vitreous. Interestingly, Nogo-A could not be detected in the vitreous of mice subjected to the model of optic nerve injury (data not shown), a lesion paradigm whose damage exclusively depends on apoptosis ${ }^{43}$. In this process, apoptotic cell bodies are phagocytosed without cytoplasmic spillover in surrounding tissues. Taken together, these results suggest that Nogo-A proteins are released by RGCs in the vitreous after excitotoxic shock.

\section{Targeting Nogo-A-Delta 20 with a function-blocking antibody improves visual recovery after retinal injury}

The detection of Nogo-A-Delta 20 in the vitreous of injured eyes suggests that it may contribute to visual function loss after injury. This region of Nogo-A strongly inhibits neuronal repair/plasticity in the $\mathrm{CNS}^{44}$ but can efficiently be neutralized in vivo using $11 C 7$ antibody ${ }^{26-29,45}$. We therefore tested the function of Nogo-A-Delta 20 in NMDAinduced visual deficits by injecting 11C7 ( $2 \mu \mathrm{g} /$ eye $)$ or an equal amount of control IgG in the mouse vitreous (Fig. 2a). In order to assess the therapeutic potential of anti-Nogo-ADelta 20 antibody in retinal injuries, our experimental design consisted of performing the injection of $11 \mathrm{C} 7$ two days after that of NMDA (Fig. 2a). Given the fast kinetic of RGC cell elimination that is usually observed after NMDA injection $^{12,13,46}$, a 2-day delay between antibody and NMDA treatment is relatively long and is thus expected to minimize the influence of $11 \mathrm{C} 7$ on RGC survival. The optokinetic response was evaluated repeatedly before and after injury to monitor visual function variations ${ }^{29,40}$. Electroretinogram recordings allowed to follow retinal cell activity upstream of $\mathrm{RGCs}^{28,38}$. A quantitative analysis of surviving RGCs was carried out on retinal flat-mounts stained for RBPMS
(Fig. 2b). In these conditions, intraocular injection of $0.5 \mathrm{nmol}$ and $2 \mathrm{nmol}$ of NMDA gave rise to moderate ( $30 \%)$ and massive ( 70\%) elimination of RGCs (Fig. 2b). The magnitude of RGC death obtained with $0.5 \mathrm{nmol}$ of NMDA in our study is similar to that observed after prolonged ocular hypertension in mouse glaucoma models, as reported by others ${ }^{47}$. As anticipated, 11C7 did not change the density of surviving RGCs at either dose of NMDA (Fig. $2 b)$. Similarly, the death of cholinergic amacrine cells was not affected by $11 \mathrm{C} 7$ in the inner nuclear layer and in the ganglion cell layer (Data not shown). However, visual function was significantly increased by $11 \mathrm{C} 7$ treatment after the injection of $0.5 \mathrm{nmol}$ of NMDA (Fig. 2c, d). After $2 \mathrm{nmol}$ of NMDA, only a trend towards an improvement could be noticed, probably due to massive neuronal cell death (Fig. 2c, d). Moreover, 11C7 did not affect ERG wave amplitudes, suggesting that it is not protective for the retinal activity generated by cells upstream of RGCs (Fig. S1). Together, these results show that inhibiting Nogo-A-Delta 20 with a single injection of $11 \mathrm{C} 7$ is sufficient to increase visual recovery without affecting neuronal survival.

\section{Nogo-A antibody inhibits monocyte-mediated inflammation in the injured retina}

In order to determine the mode of action of $11 \mathrm{C} 7$ in retinal function recovery, changes in gene expression were followed by qRT-PCR measurements, after NMDA injection $(0.5 \mathrm{nmol})$ and antibody treatments (Fig. 3a, b). We observed that $11 \mathrm{C} 7$ significantly downregulated the expression of genes involved in inflammation and monocyte activation such as those of Tnf, F4/80, Csf1, $C d 68,3$ days after injury ( $P<0.05$; ${ }^{* *} P<0.01$; Unpaired $t$ test). Strikingly, the mRNA level of $\operatorname{Tnf}$ was decreased by $\sim 70 \%$ and $\sim 80 \%$ at 3 and 7 days post injury respectively. Tnf and Sprr1a mRNA were the only transcripts that showed sustained decreases at 7 days (Fig. 3b). Interestingly, it has been proposed that Sprrla upregulation reflected the RGC response to injury ${ }^{35,48,49}$. The lower level of Sprr1a mRNA in 11C7-treated 

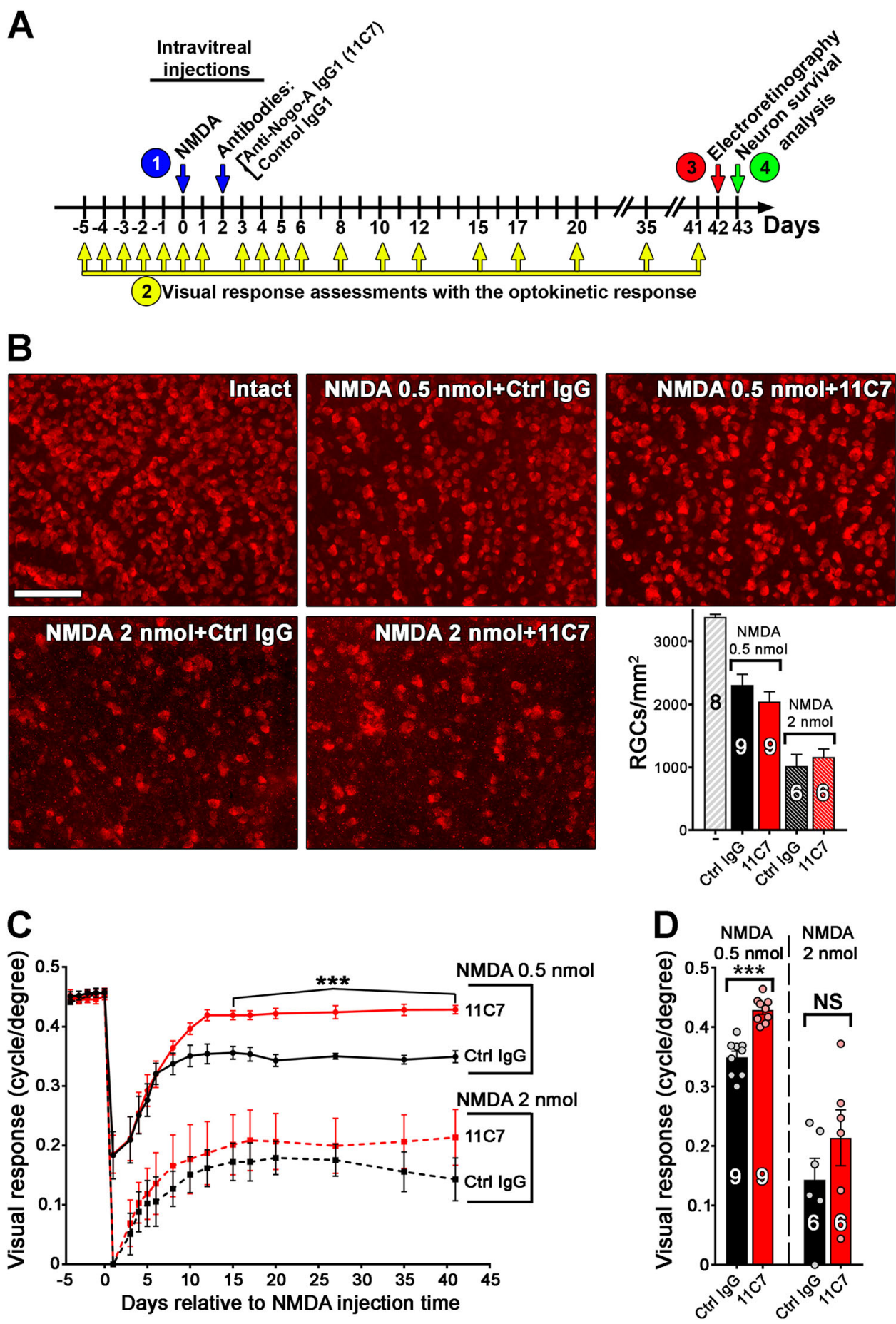

Fig. 2 (See legend on next page.)

retinae, therefore, suggests weaker RGC stress post-injury, perhaps due to TNF $\alpha$ decrease ${ }^{50}$. To further characterize TNF $\alpha$ protein changes, vitreous samples were analyzed by Western Blotting the day following antibody administration (Fig. 3c). The level of TNF $\alpha$ trimers was reduced by $\sim 70 \%$ in eyes receiving $11 \mathrm{C} 7$ compared with those injected with control IgG (Fig. 3c, ${ }^{* *} P<0.01$, unpaired $t$-test). Immunofluorescent stainings allowed to 
(see figure on previous page)

Fig. 2 Intravitreal administration of Nogo-A blocking antibody enhances visual recovery after retinal injury. a To follow visual function changes following NMDA-induced injury (1), the optokinetic response was monitored before and after intravitreal injections (2). Control lgG (2 $\mu \mathrm{g} /$ eye) or anti-Nogo-A IgG (11C7, $2 \mu \mathrm{g} /$ eye) was delivered in the vitreous 2 days after NMDA injection. Electroretinograms were recorded in photopic conditions 6 weeks after NMDA injections (3, see Fig. S1). Retinal ganglion cell survival was assessed on retinal flat-mounts stained for RBPMS, the day following ERG recordings (4). At $0.5 \mathrm{nmol}$ of NMDA, nine mice were examined for each antibody treatment (control lgG or 11C7). Six mice received control $\mathrm{lgG}$ and $11 \mathrm{C} 7$ after the injection of $2 \mathrm{nmol}$ NMDA. $\mathbf{b}$ Immunofluorescent staining with RBPMS antibody revealed a $\sim 30 \%$ reduction in the density of RGCs after injection of $0.5 \mathrm{nmol}$ of NMDA and a $~ 70-\%$ reduction following the administration of $2 \mathrm{nmol}$ of NMDA relative to intact retinae. The level of cell death did not statistically vary between the two groups receiving either 11C7 or control lgG. c The optokinetic response of mice receiving $0.5 \mathrm{nmol}$ of NMDA showed significant function deficits after control lgG treatment. Similar visual loss was obtained with $0.5 \mathrm{nmol}$ NMDA alone, without antibody (data not shown). In contrast, blocking Nogo-A with $11 \mathrm{C} 7$ allowed much better recovery of optokinetic response sensitivity. The effect of 11C7 was not significant when injected after $2 \mathrm{nmol}$ of NMDA. $\mathbf{d}$ The optokinetic response of individual animals revealed weak variability in groups injected with $0.5 \mathrm{nmol}$ of NMDA compared with $2 \mathrm{nmol}$ of NMDA. Statistics: $\mathbf{c}^{* * *} P<0.001$, two-way ANOVA; $\mathbf{d}^{* * * *} P<0.001$, unpaired $t$-test. Scale bar $=100 \mu \mathrm{m}$.

visualize TNF $\alpha$ in Iba1-expressing monocytes (macrophages/microglia) on injured retinal flat-mounts (Fig. 3d). $11 \mathrm{C} 7$ markedly decreased the intensity of TNF $\alpha$ signal in NMDA-treated retinae. Quantitatively, the number of TNF $\alpha$-expressing cells was decreased by $\sim 66 \%$ after $11 \mathrm{C} 7$ delivery compared with control IgG treatment (Fig. 4a-c). However, the number of Iba1-positive cells did not statistically differ between $11 \mathrm{C} 7$ and control IgG treatments (Fig. 4c). According to previous studies, pathological increase of TNF $\alpha$ in the retina can cause delayed and protracted degeneration of axons and oligodendrocytes in the mouse optic nerve ${ }^{47,51}$. However, the examination of olig2-positive oligodendrocytes and Smi32-positive axons did not show differences after NMDA injection and after antibody treatments (Figs. S2, S3). Combined, these results suggest that neutralizing Nogo-A-Delta 20 with a blocking antibody strongly inhibits TNF $\alpha$ expression in microglia/macrophages after retinal injury.

\section{Nogo-A modulates phosphorylation signalings controlling retinal gliosis}

We then sought to know if antibody-mediated Nogo-A blockade modified intracellular phosphorylation cascades involved in retinal cell inflammation and gliosis. To address this, Western blot analysis was focused on cofilin, an actin-severing enzyme whose phosphorylation and inactivation in microglia has been shown to prevent TNF $\alpha$ secretion $^{52}$, and Stat3 and Erk1/2 whose phosphorylation level increases in neuronal and glial cell in response to cytokine stimulation during inflammation ${ }^{53,54}$. The level of phosphorylated/inactive cofilin was dramatically increased by $11 \mathrm{C} 7$ compared with control animals receiving IgG (Fig. 5a, b). By immunofluorescence, P. cofilin appeared upregulated in Iba1-expressing microglia/macrophages on retinal sections (Fig. 5c), suggesting that TNF $\alpha$ downregulation may be due to cofilin inactivation in $11 \mathrm{C} 7$-treated eyes ${ }^{52}$. In parallel, $11 C 7$ induced $P$. Stat3 downregulation in Müller glia labeled with GS and in blood vessels stained with isolectin B4 (Fig. 5a, b, d). Stat3 is known to control vimentin and GFAP upregulation in gliotic Müller cells ${ }^{55}$. In the present study, its decrease after $11 \mathrm{C} 7$ injection may be responsible for the downregulation of vimentin and, to lower extent Gfap, mRNA (Fig. 3a). In addition, P.Erk1/2 upregulation was detected by Western Blotting in 11C7-treated retinal samples (Fig. 5a, b). This increase occurred in Müller cells as shown by the localization of P.Erk $1 / 2$ in the nucleus of GS-stained cells (Fig. 5e). P.Erk1/2 elevation may have neuroprotective functions against excitotoxicity in the retina ${ }^{56}$. Together, our results suggest that neutralizing Nogo-A with $11 \mathrm{C} 7$ counteracts signaling events controlling gliosis and inflammation.

\section{Nogo-A is upregulated in the retina of patients with diabetic retinopathy}

We then checked if the expression of Nogo-A was increased in the vitreous and in the retina of donors suffering from diabetic retinopathy (DR). At the onset of the disease, the excitotoxic elimination of RGCs and neuroinflammation are thought to mediate visual decline $^{57-59}$. Western blot analysis showed that the level of Nogo-A was increased in the vitreous of patients with diabetes, with or without diabetic retinopathy, compared with samples collected in non-diabetic subjects (Fig. 6a, b). Immunofluorescent observations were then realized on histological sections of retinae from nondiabetic (Fig. 6c) and DR patients (Fig. 6d, e). In the absence of diabetes, Nogo-A was endogenously localized in neuronal cell bodies of the ganglion cell layer and in Müller cell endfeet (Fig. 6c). GFAP-expressing astrocytes were deprived of Nogo-A staining in the nerve fiber layer (NFL) whereas GS-containing Müller cell endfeet exhibited Nogo-A fluorescence (Fig. 6c). In DR retinae, Nogo-A signal was much brighter and colocalized with GS in the endfeet and the radial processes of Müller cell (Fig. 6d). In a severe case of cystoid macular edema (CME), GFAP and Nogo-A expression colocalized in gliotic Müller cells (Fig. 6e). These results suggest that neuronal and glial Nogo-A expression may influence the development of DR in patients. 


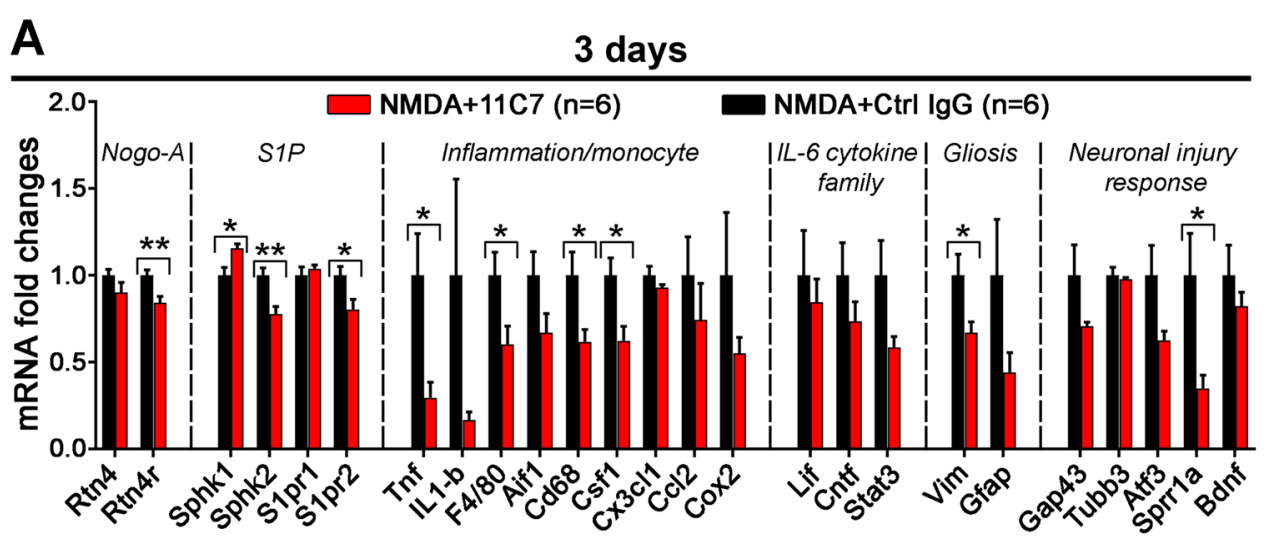

B

7 days
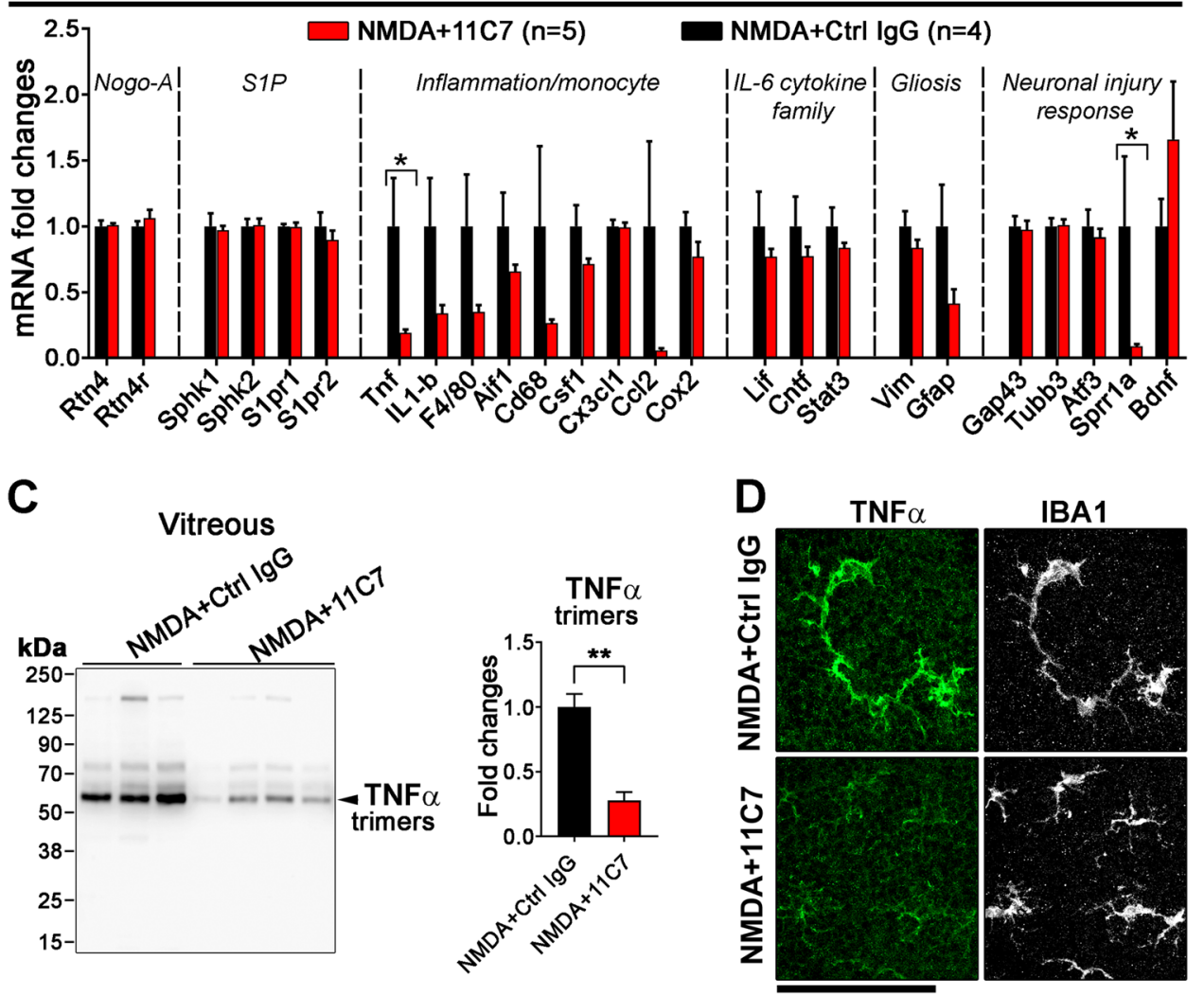

Fig. 3 Antibody-based neutralization of Nogo-A mitigates inflammation in the injured retina. $\mathbf{a}$, $\mathbf{b}$ Retinal gene expression analysis by qRT-PCR at 3 and 7 days after NMDA injection $(0.5 \mathrm{nmol})$ and antibody treatments $(2 \mu \mathrm{g} / \mathrm{eye})$. Four-six mice were used per condition. 11C7 reduced the expression of major genes involved in inflammation and monocyte activation $\left({ }^{*} P<0.05 ;{ }^{* *} P<0.01\right.$; unpaired $t$-test). In particular, $11 \mathrm{C7}$ injection led to sustained decrease of Tnf transcript and Sprr1a mRNA, the expression of which reflects the severity of neuronal injury response. c The level of TNFa trimers was studied by Western Blotting the day after antibody injection. Compared with control lgG ( $n=3$ mice), $11 \mathrm{C} 7$ injections ( $n=4$ mice) significantly decreased the content of TNFa in the vitreous of injured eyes (**P<0.01, Unpaired $t$-test). d TNFa was mainly observed in Iba1expressing monocytes by immunofluorescence on retinal flat-mounts. Its signal was much weaker with $11 \mathrm{C} 7$ than in control mice. Immunofluorescent staining observations were repeated in three different mice for each antibody treatment. Scale bar in $\mathbf{d}=100 \mu \mathrm{m}$.

\section{Discussion}

In this study, we observed the presence of Nogo-A in the mouse vitreous after NMDA-induced retinal injury. The vitreal elevation of Nogo-A occurred during inflammation characterized by TNF $\alpha$ secretion and retinal ganglion cell lysis. Strikingly, delayed injection of a function-blocking antibody directed against NogoA-Delta 20 significantly improved visual recovery. However, RGC survival was not influenced by this treatment. The analysis of inflammatory gene 


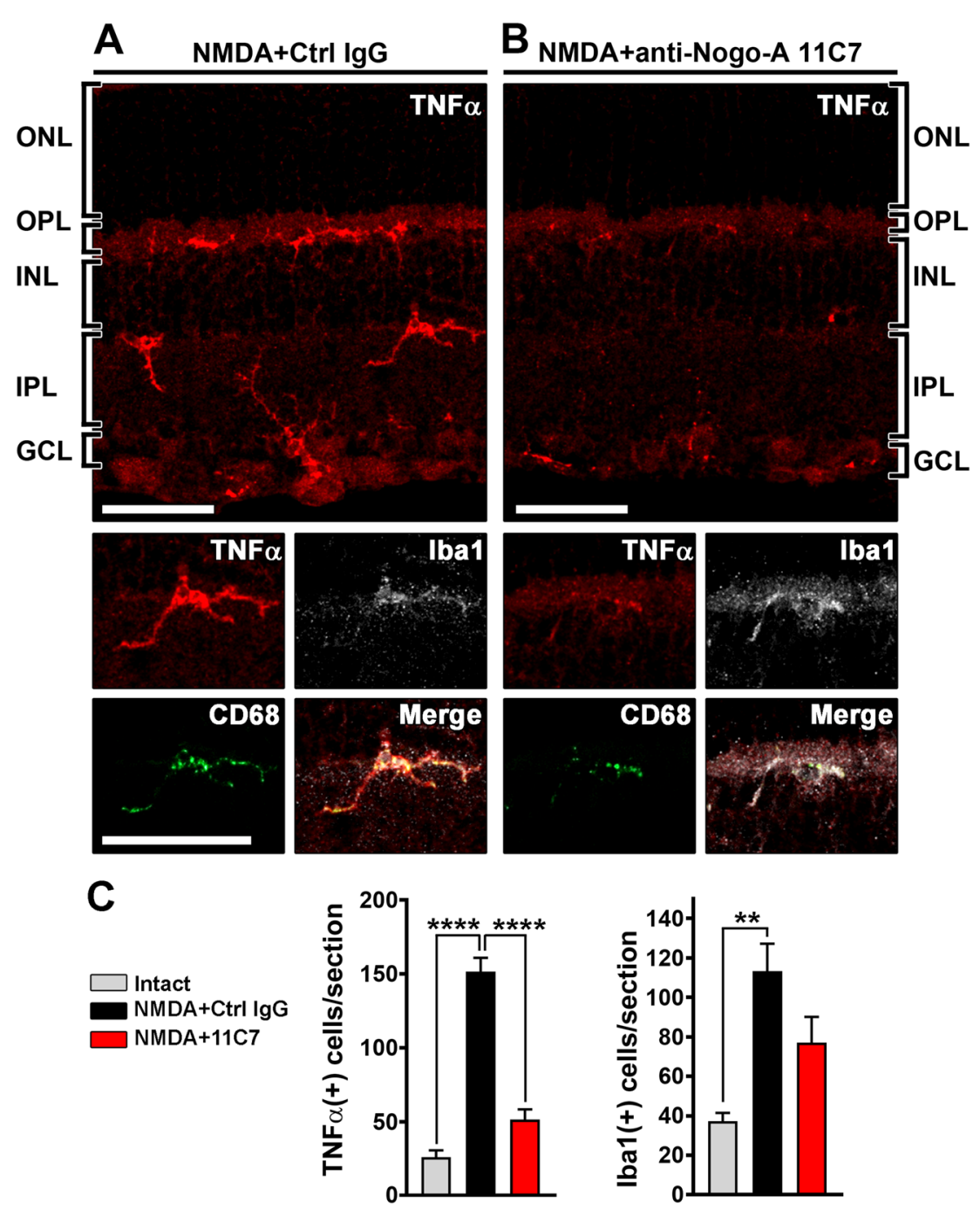

Fig. 4 Antibody-mediated Nogo-A blockade decreases the number of cells expressing TNFa without affecting the number of Iba1-positive monocytes. Cells expressing TNFa, Iba1, and CD68 were labeled on cryosections by immunofluorescence in 4 mouse retinae, $24 \mathrm{~h}$ after control lgG or 11C7 injection. a Retinal sections showed many TNFa-containing cells located in the inner retina, between the outer plexiform layer and the ganglion cell layer 1 day after control lgG injection. A majority of cells was positive for Iba1 and exhibited vesicular staining of the lysosomal protein CD68, indicating their active state. $\mathbf{b}$ The injection of 11C7 strongly attenuated TNFa and CD68 expression and to a lower extent the intensity of Iba1 in macrophages/microglia. c Quantification of the number of cells expressing TNFa and Iba1 suggesting potent and specific effects of 11C7 on TNFa cytokine reduction. Six sections were examined for each retina. Statistics: one-way ANOVA, Dunnett's post hoc test, ${ }^{* *} P<0.01 ;{ }^{* * *} P<0.0001$. Scale bars $=50 \mu \mathrm{m}$.

expression revealed strong and sustained downregulation of TNF $\alpha$ at the mRNA and protein levels in mice treated with 11C7. A pronounced decrease in TNF $\alpha$ expression was observed by immunofluorescence in microglia/macrophages and may result from cofilin inactivation. In parallel, P.Stat3 downregulation and P. Erk1/2 upregulation in Müller glia suggest that $11 \mathrm{C} 7$ attenuates gliosis as well. In general, this study shows that visual function improvement is associated with anti-inflammatory effects of Nogo-A-targeting antibody after retinal injury.
Retinal excitotoxicity increases vitreal Nogo-A proteins

In healthy conditions, Nogo-A is endogenously expressed in Müller cells and RGCs, but is weakly detectable in the vitreous. Following NMDA-induced injury, the level of Nogo-A proteins was markedly increased in the vitreous. Because Nogo-A is naturally enriched in the endoplasmic reticulum, we propose that vitreal elevation of Nogo-A may stem from RGC lysis, an event that was observed as early as $3 \mathrm{~h}$ post-NMDA injection. In contrast, other studies suggested that proteolytic degradation of Nogo-A promoted cell migration ${ }^{60}$ 


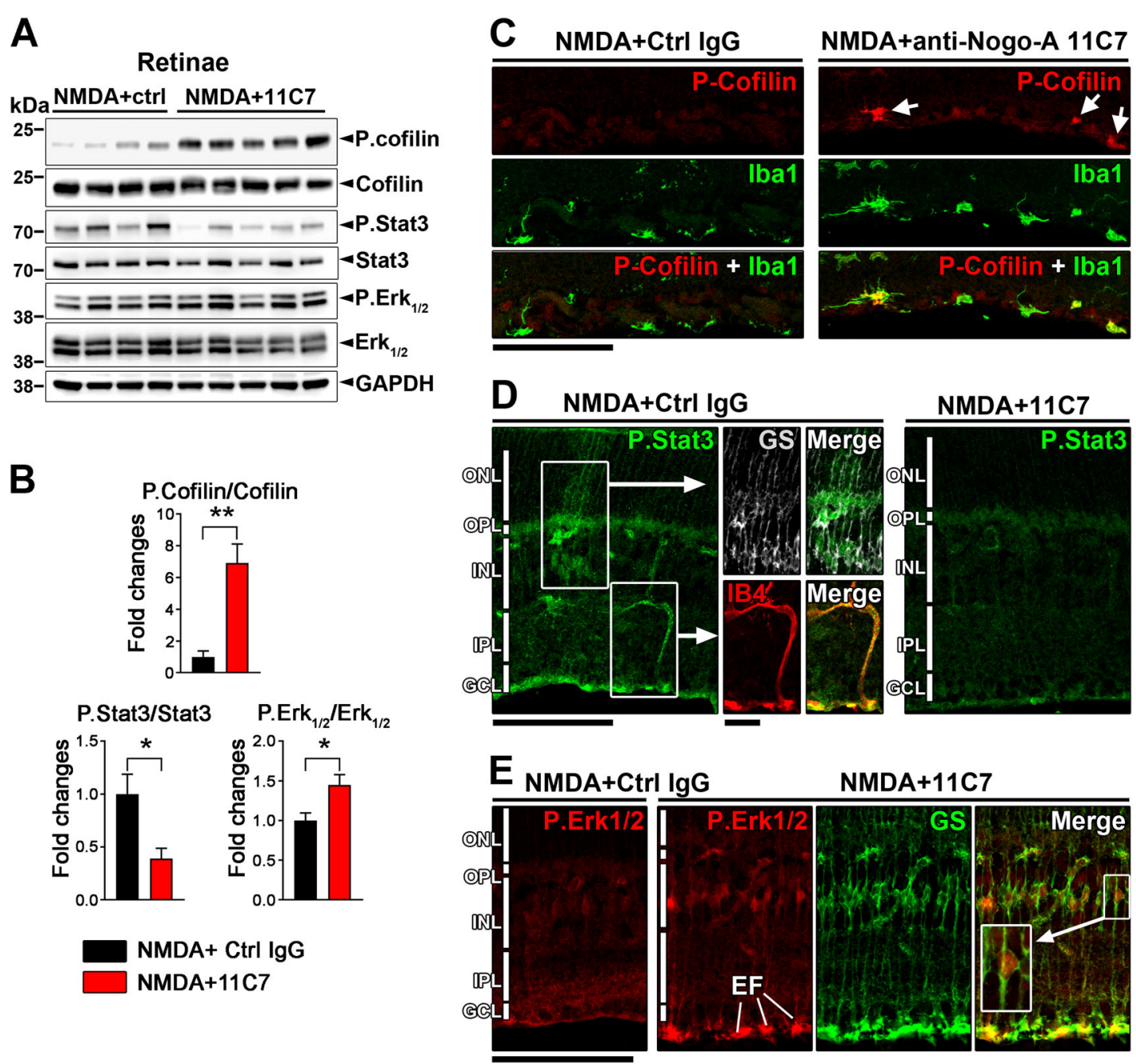

Fig. $5 \mathbf{1 1 C 7}$ treatment inhibits inflammatory processes in injured retinal glia. $\mathbf{a}$, $\mathbf{b}$ Western blot analysis of whole retina lysates allowed to detect marked changes in the phosphorylation level of cofilin, P.Stat3 and P.Erk1/2 after NMDA/11C7 injection ( $n=5$ mice) compared with control eye treated with NMDA/control IgG ( $n=4$ mice). In its phosphorylated state, cofilin is inactivated by $11 \mathrm{C} 7$. In parallel, P.Stat3 downregulation suggests cytokine signaling reduction. c By immunofluorescence on retinal cross sections, P.cofilin upregulation was visualized in microglia/ macrophages labeled with Iba1 (arrows). d P.Stat3 decrease was from Müller glia positive for glutamine synthetase (GS) and from isolectin B4 (IB4)labeled blood vessels. e Following NMDA and 11C7 treatments, P.Erk1/2 immunoreactivity increased in the nucleus and in the endfeet (EF) of Müller cells identified with cytoplasmic GS. Immunofluorescent stainings were repeated in 3 mice/condition. Scales bars: $\mathbf{c}-\mathbf{e}=100 \mu \mathrm{m}$, close-up in $\mathbf{d}=$ $25 \mu \mathrm{m}$. ONL, outer nuclear layer; OPL, outer plexiform layer; INL, inner nuclear layer; IPL, inner plexiform layer; $G C L$, ganglion cell layer. Statistics: ${ }^{*} P<$ 0.05 ; ${ }^{* *} P<0.01$; Unpaired $t$-test.

and axonal regeneration ${ }^{61}$. However, in these two last studies, growth activation was obtained in particular conditions, depending on the use of invasive glioblastoma cells ${ }^{60}$ and Schwann cells that stimulate axonal regeneration in the sciatic nerve ${ }^{61}$. It is conceivable that NogoA cleavage gives rise to the release of inhibitory fragments contributing to vision loss in the injured eye and that some growth-promoting treatments have the ability to inactivate them by alternative proteolysis. In the present study, vitreal Nogo-A was detected with 11C7, an antibody that selectively binds Delta 20 inhibitory domain $^{16,62}$. In blocking experiments, $11 \mathrm{C} 7$ significantly increased visual function, suggesting that vitreal Nogo-ADelta 20-containing proteins are active in inhibiting retinal neuron recovery. To our knowledge, these findings represent the first hint that active Nogo-A-Delta 20 can be released in biological fluids and diffuse in injured CNS tissues. Therefore, we wonder if the release of Nogo-A proteins also participate in the neurological alterations caused by brain injuries involving excitotoxicity such as cerebral stroke. Indeed, $11 \mathrm{C} 7$ can improve function recovery in stroke models ${ }^{23-25}$ in which massive neuronal necrosis produces tremendous inflammation mediated by $\mathrm{TNF}^{63}$. In future studies, it will be important to fully 

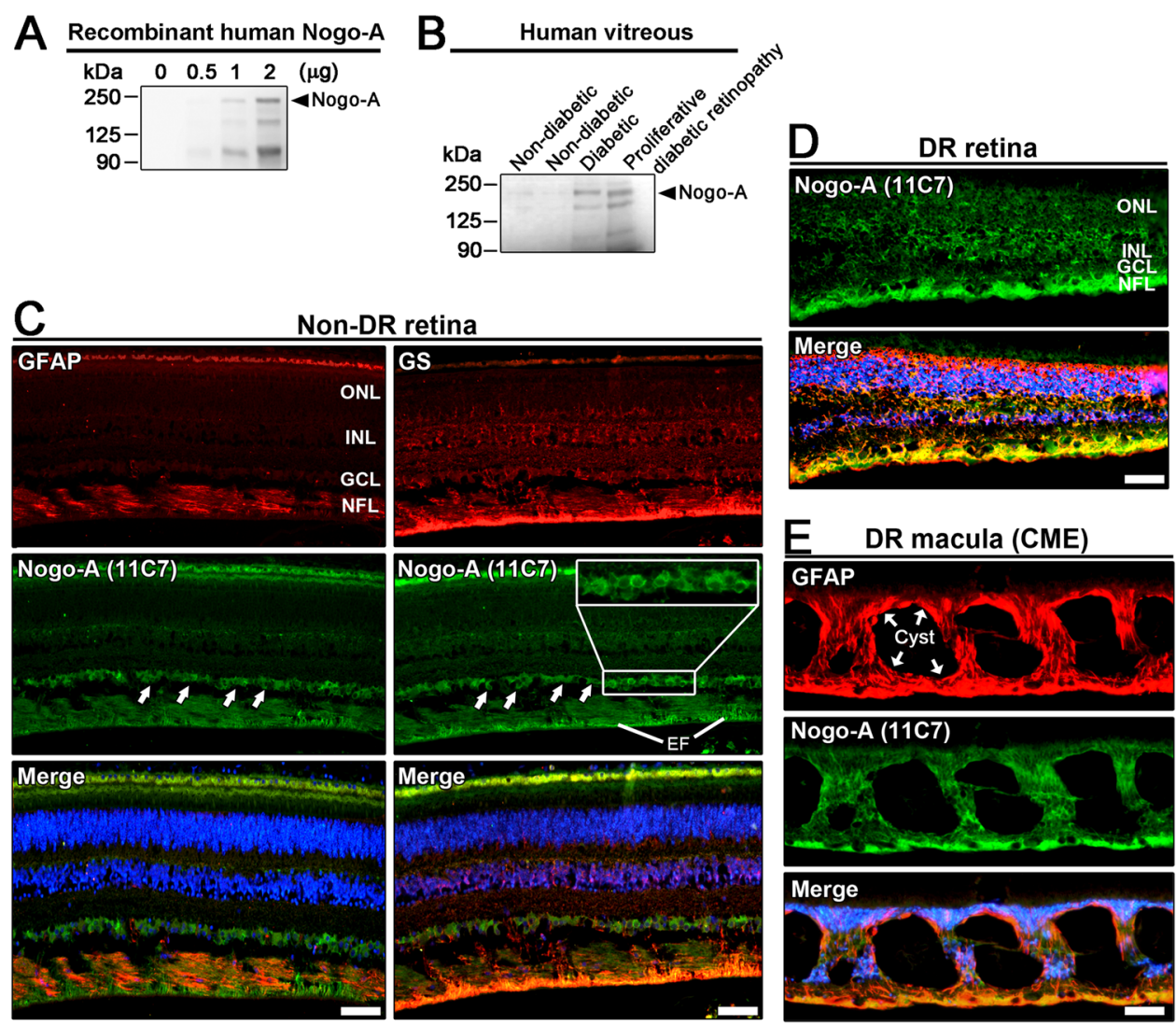

Fig. 6 Nogo-A protein is increased in the vitreous and in the retina of patients affected by diabetic retinopathy. a Western blot analysis was carried out to detect Nogo-A protein in the vitreous of donors. Anti-Nogo-A antibody allowed to detect recombinant human Nogo-A protein. $\mathbf{b}$ In the vitreous of non-diabetic patients, Nogo-A signal was very weak in comparison to patients with diabetes and proliferative diabetic retinopathy. c Immunofluorescent stainings in human retinal sections allowed to visualize Nogo-A in cell bodies (arrows) of the ganglion cell layer (GCL) and in Müller cell endfeet (EF). Dapi was used to recognize retinal cell layers in blue. To distinguish astrocytes from Müller cell processes in the nerve fiber layer (NFL), GFAP and GS were used respectively as specific cell markers. Without diabetes, astrocytes are the only glia expressing GFAP. They were deprived of Nogo-A staining. In contrast, Nogo-A was colocalized with GS in Müller cell endfeet. $\mathbf{d}$ In the retina of a diabetic patient, Nogo-A and GS were upregulated in Müller cells whose radial processes span the whole retinal thickness. e In the macula of a diabetic retinopathy (DR) patient, severe cystoid macular edema (CME) was observed. Around prominent cysts, Nogo-A and GFAP expression was strongly upregulated in gliotic Müller cells. These observations link Nogo-A expression increase with different stages of diabetic retinopathy. Scale bars $=20 \mu \mathrm{m}$.

evaluate the therapeutic potential of Nogo-A-neutralizing antibodies by determining if they can modulate neuroinflammation in stroke and spinal injury.

Subsequently to proteolytic cleavage, the fate of NogoA-Delta 20-containing proteins has not been addressed in our study. A previous study showed that recombinant Nogo-A-Delta 20 could activate RhoA signaling in neurons upon internalization, thereby inducing growth cone collapse in vitro ${ }^{64}$. Similarly in the retina, endocytosis of Nogo-A-Delta 20 in RGCs and its subsequent axonal transport in vesicles may lead to the inhibition of retinogeniculate terminal plasticity. This mechanism deserves to be tested in the injured visual system. It may allow to explain why the plasticity of RGC terminals is increased in the dorso lateral geniculate nucleus of Nogo-A KO mice after monocular deprivation, for example ${ }^{36}$. A similar mechanism may operate after retinal excitotoxicity.

\section{Intraocular inhibition of Nogo-A with blocking antibody} promotes visual recovery

Delayed blockade of Nogo-A with a single injection of neutralizing antibody was sufficient to promote visual function improvement after retinal injury. This is consistent with our previous results showing that Nogo-A gene deletion allowed better visual recovery in $\mathrm{KO}$ mice after NMDA-induced injury ${ }^{29}$. Based on previous observations, a participation of cortical Nogo-A in the restriction of vision recovery remains possible ${ }^{65}$. However, our study reveals that local expression of Nogo-A in the retina contributes to the development of visual deficits after retinal injury.

It is important to underscore the fact that visual improvement was only observed when RGC cell death was $\sim 30 \%$ (0.5 nmol NMDA), but not when RGC loss reached $\sim 70 \%$ ( $2 \mathrm{nmol} \mathrm{NMDA})$. Of course, the effects of 
$11 \mathrm{C} 7$ on visual recovery may depend on the level of RGC survival. However, even after the elimination of $~ 70 \%$ of RGCs, a reduced but still measurable OKR was recorded. In this case, additional factors may explain the lack of OKR improvement with $11 \mathrm{C} 7$ treatment. In fact, contrary to what has been observed after the injection of $0.5 \mathrm{nmol}$ of NMDA, retinal cell death is not limited to the ganglion cell layer after the delivery of $2 \mathrm{nmol}$ of NMDA, but spread to amacrine cells in the ganglion cell layer and in the inner nuclear layer ${ }^{29}$. In particular, the loss of cholinergic amacrine cells called starburst amacrine cells may cause major OKR decrease. These cells are involved in motion detection and are essential to generate the optokinetic response ${ }^{66}$. Other neurons such as bipolar cells, involved in the production of the ERG b-wave, may be impaired by $2 \mathrm{nmol}$ of NMDA. Indeed, at doses higher than $0.5 \mathrm{nmol}$, an important functional change associated with NMDA toxicity in the inner nuclear layer was the reduction of ERG b-wave amplitude ${ }^{29}$. In contrast, $0.5 \mathrm{nmol}$ NMDA did not significantly influence ERG bwave amplitudes compared with PBS injection (data not shown). The decrease in ERG b-wave amplitude noticed after $0.5 \mathrm{nmol}$ NMDA and antibody injections is not the result of retinal damage in the inner nuclear layer but is rather attributable to the injection itself.

In addition, it is important to mention that the effect of $11 \mathrm{C} 7$ on visual function enhancement is not restricted to the optokinetic response, a reflexive neck movement induced by the accessory optic system in the brainstem. In a previous study, we found that intravitreally-delivered $11 \mathrm{C7}$ also improved visual cortex response after NMDAinduced retinal excitotoxicity, as shown by the reduction of visual evoked potential latency ${ }^{29}$. Therefore, conscious and non-conscious visual functions may be improved by the blockade of retinal Nogo-A with $11 \mathrm{C} 7$ after ocular injury.

\section{Switch in microglia and Müller glia reaction to injury}

Our data showed that the reaction of microglia/macrophages and Müller cell are profoundly modified by $11 \mathrm{C} 7$. For microglia/macrophages, the most striking change was the downregulation of TNF $\alpha$ expression in injured retinae. The enhancement of TNF $\alpha$ expression in microglia is a major event controlling retinal excitotoxicity ${ }^{67}$. The elimination or the inhibition of microglia has been shown to prevent NMDA-induced TNFo upregulation in the retina and to protect RGCs from cell death ${ }^{67}$. Given the strong decrease in TNF $\alpha$ expression observed after 11C7 injection, Nogo-A-Delta 20 appears as a new potent modulator of TNF $\alpha$ expression in microglia. Moreover, the decrease of TNF $\alpha$ expression was correlated with cofilin inactivation by phosphorylation. The secretion of TNF $\alpha$ has been shown to be driven by cofilin activation/dephosphorylation in LPSinduced microglia activation ${ }^{52}$. In a similar fashion, $11 \mathrm{C} 7$ may reduce the level of TNF $\alpha$ by inactivating cofilin in microglia/macrophages in the retina. Along with TNF $\alpha$, Sprrla is the protein whose gene expression was the most downregulated by $11 \mathrm{C} 7$ at 7 days post-NMDA delivery. Interestingly, the expression of Sprrla could be influenced by TNF $\alpha$ in inflammation ${ }^{50}$. It is thus tempting to propose that Nogo-A-Delta 20/P.cofilin/TNF $\alpha /$ Sprrla may be a stress signaling pathway mediating chronic RGC dysfunction in the injured retina and that may be reversed by $11 \mathrm{C} 7$ treatment.

Following retinal injury, TNF $\alpha$ can exert rapid and delayed effects in the development of visual impairments, respectively by regulating RGC death ${ }^{46}$ and by causing oligodendrocyte and optic nerve axon degeneration ${ }^{51}$. Significant loss of axons and oligodendrocytes has been observed in the optic nerve 2 weeks after intravitreal injection of recombinant TNF $\alpha$, whereas a significant decline in RGC number was only noticed after 2 months ${ }^{47,51}$. Visual function changes have not been followed in these studies. However, we believe that the late visual function improvement that arose at 2 weeks after NMDA injection (12 days after antibody injection) in 11C7-treated mice might result from TNFo downregulation. Unfortunately, in our study, immunofluorescent analysis of optic nerve axons and oligodendrocytes did not allow to find differences between mice receiving $11 \mathrm{C} 7$ and control antibody to support this hypothesis. Given the slow progression of axon/oligodendrocyte degeneration initiated by TNF $\alpha$ injections, the histological observations of optic nerves in our study may have been carried out too early ( 42 days post injury) to detect cellular damage. Alternatively, we propose that $11 \mathrm{C} 7$ may improve vision by preserving the integrity of optic nerve oligodendrocyte-axon contacts at the level of the Nodes of Ranvier. The maintenance of the Nodes of Ranvier in the optic nerve is crucial to ensure action potential conduction from the eye to visual brain regions and thus allow visual information integration. For example, when the Nodes of Ranvier are altered in the optic nerve after retinal ischemia, the optokinetic response is markedly impaired ${ }^{40}$. Interestingly, we have previously reported that intravitreal administration of $11 \mathrm{C} 7$ reduced visual evoked potential latency in the visual cortex after NMDA-induced excitotoxicity ${ }^{29}$. This observation may result from faster action potential transfer to brain targets. Since intravitreal injection of TNF $\alpha$ can trigger optic nerve demyelination ${ }^{68}, 11 C 7$-induced TNF $\alpha$ downregulation may lead to a better protection of myelin and the Nodes of Ranvier after excitotoxic injury. This possibility deserves to be addressed in future studies to clarify the mechanisms of action of $11 \mathrm{C} 7$ on visual recovery.

\section{Therapeutic potential of Nogo-A-targeting antibodies in the treatment of retinal diseases}

Collectively, the present study and others ${ }^{28,29}$ tend to suggest that Nogo-A may be a relevant molecular target 
to treat proliferative and non-proliferative diabetic retinopathy. Indeed, Nogo-A expression was dramatically increased in the retina and vitreous of donors with diabetic retinopathy (present study), 2) very similar retinal damages to those produced in our study with NMDA are thought to occur in diabetic retinopathy ${ }^{5-7,10}$. In addition, we have previously demonstrated that $11 \mathrm{C} 7$ strongly restricted retinal neovascularization in the model of oxygen-induced retinopathy ${ }^{28}$. Therefore, intravitreal injection of Nogo-A-blocking antibody may reduce neuronal dysfunction and may prevent pathological neovascularization, that are two hallmarks of diabetic retinopathy. In future studies, the effects of Nogo-A antibodies should be assessed in chronic models of diabetic retinopathy involving progressive loss of RGCs and depend on NMDAR activation ${ }^{2,3}$.

\section{Conclusion}

Our results demonstrate that intravitreal injection of anti-Nogo-A antibody can improve visual function and reduce microglia/macrophage-mediated inflammation after retinal injury. These data may be useful to develop new therapeutic approaches for diabetic retinopathy or neurodegenerative diseases with an important inflammatory component.

\begin{abstract}
Acknowledgements
This work was supported by grants from the Fonds de recherche du QuébecSanté (FRQS, grant\# 30633 to V.P.), the Canadian Research Health Institutes (CIHR, grant\# 407687 to V.P.), the Vision Health Research Network (VHRN, National and International Networking program, to V.P.) of the Fonds de recherche du Québec-Santé, the Canada Foundation for Innovation (CFI, project\# 34204 to V.P.). We thank Prof. Martin E. Schwab (Univ of Zurich, Switzerland) for providing us with 11C7 antibody, Prof. Serge Rivest (Univ Laval, Canada) for sharing with us his confocal microscope and Prof. Emmanuel Planel and Prof. Sébastien Hébert (Univ Laval, Canada) for allowing us to use their fluorescent microscope and GRT-PCR machine.
\end{abstract}

\section{Conflict of interest}

The authors declare that they have no conflict of interest.

\section{Publisher's note}

Springer Nature remains neutral with regard to jurisdictional claims in published maps and institutional affiliations.

Supplementary Information accompanies this paper at (https://doi.org/ 10.1038/s41419-020-2302-x).

Received: 13 September 2019 Revised: 21 January 2020 Accepted: 23 January 2020

Published online: 06 February 2020

\section{References}

1. Wang, R. \& Reddy, P. H. Role of glutamate and NMDA receptors in Alzheimer's disease. J. Alzheimers Dis. 57, 1041-1048 (2017).

2. Harada, C. et al. ASK1 deficiency attenuates neural cell death in GLASTdeficient mice, a model of normal tension glaucoma. Cell Death Differ. 17 1751-1759 (2010).

3. Harada, T. et al. The potential role of glutamate transporters in the pathogenesis of normal tension glaucoma. J. Clin. Invest 117, 1763-1770 (2007).
4. Parsons, M. P. \& Raymond, L. A. Extrasynaptic NMDA receptor involvement in central nervous system disorders. Neuron 82, 279-293 (2014).

5. Ambati, J. et al. Elevated gamma-aminobutyric acid, glutamate, and vascular endothelial growth factor levels in the vitreous of patients with proliferative diabetic retinopathy. Arch. Ophthalmol. 115, 1161-1166 (1997).

6. Kusari, J., Zhou, S., Padillo, E., Clarke, K. G. \& Gil, D. W. Effect of memantine on neuroretinal function and retinal vascular changes of streptozotocin-induced diabetic rats. Invest Ophthalmol. Vis. Sci. 48, 5152-5159 (2007).

7. Lieth, E. et al. Glial reactivity and impaired glutamate metabolism in short-term experimental diabetic retinopathy. Penn State Retina Research Group. Diabetes 47, 815-820 (1998).

8. Siliprandi, R. et al. N-methyl-D-aspartate-induced neurotoxicity in the adult rat retina. Vis. Neurosci. 8, 567-573 (1992).

9. Joo, C. K. et al. Necrosis and apoptosis after retinal ischemia: involvement of NMDA-mediated excitotoxicity and p53. Invest Ophthalmol. Vis. Sci. 40, 713-720 (1999).

10. Li, Q. \& Puro, D. G. Diabetes-induced dysfunction of the glutamate transporter in retinal Muller cells. Invest Ophthalmol. Vis. Sci. 43, 3109-3116 (2002).

11. Lucas, D. R. \& Newhouse, J. P. The toxic effect of sodium L-glutamate on the inner layers of the retina. AMA Arch. Ophthalmol. 58, 193-201 (1957).

12. Pernet, V., Bourgeois, P. \& Di Polo, A. A role for polyamines in retinal ganglion cell excitotoxic death. J. Neurochem. 103, 1481-1490 (2007).

13. Manabe, S. \& Lipton, S. A. Divergent NMDA signals leading to proapoptotic and antiapoptotic pathways in the rat retina. Invest Ophthalmol. Vis. Sci. 44, 385-392 (2003).

14. Chen, M. S. et al. Nogo-A is a myelin-associated neurite outgrowth inhibitor and an antigen for monoclonal antibody IN-1. Nature 403, 434-439 (2000).

15. GrandPre, T., Nakamura, F., Vartanian, T. \& Strittmatter, S. M. Identification of the Nogo inhibitor of axon regeneration as a Reticulon protein. Nature 403, 439-444 (2000).

16. Oertle, T. et al. Nogo-A inhibits neurite outgrowth and cell spreading with three discrete regions. J. Neurosci. 23, 5393-5406 (2003).

17. Fournier, A. E., GrandPre, T. \& Strittmatter, S. M. Identification of a receptor mediating Nogo-66 inhibition of axonal regeneration. Nature 409, 341-346 (2001).

18. $\mathrm{Mi}$, S. et al. LINGO-1 is a component of the Nogo-66 receptor/p75 signaling complex. Nat. Neurosci. 7, 221-228 (2004)

19. Shao, Z. et al. TAJ/TROY, an orphan TNF receptor family member, binds Nogo-66 receptor 1 and regulates axonal regeneration. Neuron 45, 353-359 (2005).

20. Wang, K. C., Kim, J. A., Sivasankaran, R., Segal, R. \& He, Z. P75 interacts with the Nogo receptor as a co-receptor for Nogo, MAG and OMgp. Nature 420, 74-78 (2002).

21. Yamashita, T., Fujitani, M., Yamagishi, S., Hata, K. \& Mimura, F. Multiple signals regulate axon regeneration through the Nogo receptor complex. Mol. Neurobiol. 32, 105-111 (2005).

22. Kempf, A. et al. The sphingolipid receptor S1PR2 is a receptor for Nogo-a repressing synaptic plasticity. PLoS Biol. 12, e1001763 (2014).

23. Tsai, S. Y., Papadopoulos, C. M., Schwab, M. E. \& Kartje, G. L. Delayed anti-nogoa therapy improves function after chronic stroke in adult rats. Stroke $\mathbf{4 2}$ 186-190 (2011).

24. Markus, T. M. et al. Recovery and brain reorganization after stroke in adult and aged rats. Ann. Neurol. 58, 950-953 (2005).

25. Lindau, N. T. et al. Rewiring of the corticospinal tract in the adult rat after unilateral stroke and anti-Nogo-A therapy. Brain 137, 739-756 (2014).

26. Liebscher, T. et al. Nogo-A antibody improves regeneration and locomotion of spinal cord-injured rats. Ann. Neurol. 58, 706-719 (2005).

27. Gonzenbach, R. R. et al. Delayed anti-nogo-a antibody application after spinal cord injury shows progressive loss of responsiveness. J. Neurotrauma 29, 567-578 (2012).

28. Joly, S., Dejda, A., Rodriguez, L., Sapieha, P. \& Pernet, V. Nogo-A inhibits vascular regeneration in ischemic retinopathy. Glia. https://doi.org/10.1002/glia.23462 (2018).

29. Mdzomba, J. B. et al. Nogo-A inactivation improves visual plasticity and recovery after retinal injury. Cell Death Dis. 9, 727 (2018).

30. Joly, S., Dodd, D. A., Grewe, B. F. \& Pernet, V. Reticulon 4ANNogo-A influences the distribution of Kir4.1 but is not essential for potassium conductance in retinal Muller glia. Neurosci. Lett. 627, 168-177 (2016).

31. Pernet, V., Joly, S., Christ, F., Dimou, L. \& Schwab, M. E. Nogo-A and myelinassociated glycoprotein differently regulate oligodendrocyte maturation and myelin formation. J. Neurosci. 28, 7435-7444 (2008). 
32. Pernet, $V$. et al. Neuronal Nogo-A upregulation does not contribute to ER stress-associated apoptosis but participates in the regenerative response in the axotomized adult retina. Cell Death Differ. 19, 1096-1108 (2012).

33. Vajda, F. et al. Cell type-specific Nogo-A gene ablation promotes axonal regeneration in the injured adult optic nerve. Cell Death Differ. 22, 323-335 (2015).

34. Joly, S. \& Pernet, V. Sphingosine 1-phosphate receptor 1 is required for retinal ganglion cell survival after optic nerve trauma. J. Neurochem 138, 571-586 (2016).

35. Pernet, $\mathrm{V}$. et al. Misguidance and modulation of axonal regeneration by Stat3 and Rho/ROCK signaling in the transparent optic nerve. Cell Death Dis. 4, e734 (2013).

36. Guzik-Kornacka, A. et al. Nogo-A deletion increases the plasticity of the optokinetic response and changes retinal projection organization in the adult mouse visual system. Brain Struct. Funct. 221, 317-329 (2016).

37. Prusky, G. T., Alam, N. M., Beekman, S. \& Douglas, R. M. Rapid quantification of adult and developing mouse spatial vision using a virtual optomotor system. Invest Ophthalmol. Vis. Sci. 45, 4611-4616 (2004).

38. Joly, S., Lamoureux, S. \& Pernet, V. Nonamyloidogenic processing of amyloid beta precursor protein is associated with retinal function improvement in aging male APPswe/PS1DeltaE9 mice. Neurobiol. Aging 53, 181-191 (2017).

39. Kwong, J. M., Caprioli, J. \& Piri, N. RNA binding protein with multiple splicing: a new marker for retinal ganglion cells. Invest Ophthalmol. Vis. Sci. 51, 1052-1058 (2010).

40. Joly, S., Guzik-Kornacka, A., Schwab, M. E. \& Pernet, V. New mouse retinal stroke model reveals direction-selective circuit damage linked to permanent optokinetic response loss. Invest Ophthalmol. Vis. Sci. 55, 4476-4489 (2014).

41. Zhang, C. et al. STAT3 activation protects retinal ganglion cell layer neurons in response to stress. Exp. Eye Res. 86, 991-997 (2008).

42. Nakazawa, T. et al. Attenuated glial reactions and photoreceptor degeneration after retinal detachment in mice deficient in glial fibrillary acidic protein and vimentin. Invest Ophthalmol. Vis. Sci. 48, 2760-2768 (2007).

43. Berkelaar, M., Clarke, D. B., Wang, Y. C., Bray, G. M. \& Aguayo, A. J. Axotomy results in delayed death and apoptosis of retinal ganglion cells in adult rats. J. Neurosci. 14, 4368-4374 (1994).

44. Schwab, M. E. Functions of Nogo proteins and their receptors in the nervous system. Nat. Rev. Neurosci. 11, 799-811 (2010).

45. Walchli, T. et al. Nogo-A is a negative regulator of CNS angiogenesis. Proc. Natl Acad. Sci. USA 110, E1943-E1952 (2013).

46. Lebrun-Julien, F. et al. Excitotoxic death of retinal neurons in vivo occurs via a non-cell-autonomous mechanism. J. Neurosci. 29, 5536-5545 (2009).

47. Nakazawa, T. et al. Tumor necrosis factor-alpha mediates oligodendrocyte death and delayed retinal ganglion cell loss in a mouse model of glaucoma. J. Neurosci. 26, 12633-12641 (2006).

48. Leibinger, M., Andreadaki, A., Diekmann, H. \& Fischer, D. Neuronal STAT3 activation is essential for CNTF- and inflammatory stimulation-induced CNS axon regeneration. Cell Death Dis. 4, e805 (2013).

49. Pernet, $\mathrm{V}$. et al. Long-distance axonal regeneration induced by CNTF gene transfer is impaired by axonal misguidance in the injured adult optic nerve. Neurobiol. Dis. 51, 202-213 (2013).

50. Ramakrishnan, V. R. et al. RNA sequencing and pathway analysis identify tumor necrosis factor alpha driven small proline-rich protein dysregulation in chronic rhinosinusitis. Am. J. Rhinol. Allergy $\mathbf{3 1}$ 283-288 (2017).

51. Kitaoka, Y. et al. TNF-alpha-induced optic nerve degeneration and nuclear factor-kappaB p65. Invest Ophthalmol. Vis. Sci. 47, 1448-1457 (2006).

52. Alhadidi, Q. \& Shah, Z. A. Cofilin mediates LPS-induced microglial cell activation and associated neurotoxicity through activation of NF-kappaB and JAKSTAT pathway. Mol. Neurobiol. 55, 1676-1691 (2018).

53. Peterson, W. M., Wang, Q., Tzekova, R. \& Wiegand, S. J. Ciliary neurotrophic factor and stress stimuli activate the Jak-STAT pathway in retinal neurons and glia. J. Neurosci. 20, 4081-4090 (2000).

54. Guo, D., Dunbar, J. D., Yang, C. H., Pfeffer, L. M. \& Donner, D. B. Induction of Jak/ STAT signaling by activation of the type 1 TNF receptor. J. Immunol. 160, 2742-2750 (1998).

55. Kirsch, M., Trautmann, N., Ernst, M. \& Hofmann, H. D. Involvement of gp130associated cytokine signaling in Muller cell activation following optic nerve lesion. Glia 58, 768-779 (2010).

56. Fischer, A. J., Scott, M. A., Ritchey, E. R. \& Sherwood, P. Mitogen-activated protein kinase-signaling regulates the ability of Muller glia to proliferate and protect retinal neurons against excitotoxicity. Glia 57, 1538-1552 (2009).

57. Barber, A. J. et al. Neural apoptosis in the retina during experimental and human diabetes. Early onset and effect of insulin. J. Clin. Invest 102, 783-791 (1998).

58. Ng, D. S. et al. Retinal ganglion cell neuronal damage in diabetes and diabetic retinopathy. Clin. Exp. Ophthalmol. 44, 243-250 (2016).

59. Sohn, E. H. et al. Retinal neurodegeneration may precede microvascular changes characteristic of diabetic retinopathy in diabetes mellitus. Proc. Natl Acad. Sci. USA 113, E2655-E2664 (2016).

60. Belien, A. T., Paganetti, P. A. \& Schwab, M. E. Membrane-type 1 matrix metalloprotease (MT1-MMP) enables invasive migration of glioma cells in central nervous system white matter. J. Cell Biol. 144, 373-384 (1999).

61. Ahmed, Z. et al. Schwann cell-derived factor-induced modulation of the NgR/ p75NTR/EGFR axis disinhibits axon growth through CNS myelin in vivo and in vitro. Brain 129, 1517-1533 (2006).

62. Dodd, D. A. et al. Nogo-A, $-B$, and $-C$ are found on the cell surface and interact together in many different cell types. J. Biol. Chem. 280, 12494-12502 (2005).

63. Lambertsen, K. L., Biber, K. \& Finsen, B. Inflammatory cytokines in experimental and human stroke. J. Cereb. Blood Flow. Metab. 32, 1677-1698 (2012).

64. Joset, A., Dodd, D. A., Halegoua, S. \& Schwab, M. E. Pincher-generated Nogo-A endosomes mediate growth cone collapse and retrograde signaling. J. Cell Biol. 188, 271-285 (2010).

65. McGee, A. W., Yang, Y., Fischer, Q. S., Daw, N. W. \& Strittmatter, S. M. Experience-driven plasticity of visual cortex limited by myelin and Nogo receptor. Science 309, 2222-2226 (2005).

66. Yoshida, K. et al. A key role of starburst amacrine cells in originating retinal directional selectivity and optokinetic eye movement. Neuron 30, 771-780 (2001).

67. Takeda, A. et al. Microglia mediate non-cell-autonomous cell death of retinal ganglion cells. Glia 66, 2366-2384 (2018).

68. Butt, A. M. \& Jenkins, H. G. Morphological changes in oligodendrocytes in the intact mouse optic nerve following intravitreal injection of tumour necrosis factor. J. Neuroimmunol. 51, 27-33 (1994). 